\title{
Article \\ Model Predictive Control of Active Suspension for an Electric Vehicle Considering Influence of Braking Intensity
}

\author{
Junjiang Zhang ${ }^{1}$, Yang Yang ${ }^{1,2, *}$, Minghui Hu ${ }^{1,2}$, Chunyun Fu ${ }^{1,2}$ and Jun Zhai ${ }^{3}$ \\ 1 School of Automotive Engineering, Chongqing University, Chongqing 400044, China; \\ zhangjunjiang2020@163.com (J.Z.); minghui_h@163.com (M.H.); fuchunyun@cqu.edu.cn (C.F.) \\ 2 State Key Laboratory of Mechanical Transmissions, Chongqing University, Chongqing 400044, China \\ 3 Chongqing Changan Automobile Co., Ltd., Chongqing 400023, China; zhaijun@changan.com.cn \\ * Correspondence: yangyang@cqu.edu.cn; Tel.: +86-136-0831-1819
}

check for

updates

Citation: Zhang, J.; Yang, Y.; Hu, M.; Fu, C.; Zhai, J. Model Predictive Control of Active Suspension for an Electric Vehicle Considering Influence of Braking Intensity. Appl. Sci. 2021, 11, 52. https://dx.doi.org/10.3390/app11010052

Received: 17 October 2020

Accepted: 17 December 2020

Published: 23 December 2020

Publisher's Note: MDPI stays neutral with regard to jurisdictional claims in published maps and institutional affiliations.

Copyright: (c) 2020 by the authors. Licensee MDPI, Basel, Switzerland. This article is an open access article distributed under the terms and conditions of the Creative Commons Attribution (CC BY) license (https: / / creativecommons.org/ licenses/by/4.0/).

\begin{abstract}
In the process of vehicle braking, braking intensity has a significant impact on vehicle comfort, and studies on this aspect have been limited. Therefore, an equivalent 4-degree-of-freedom half-vehicle model including the braking intensity influence was established in this study. Subsequently, considering braking intensity as the interference quantity that is the uncontrollable input, a model predictive control (MPC) strategy in which the vertical velocities of front body, rear body, front wheel, and rear wheel are the control targets was proposed. Based on Lyapunov's stability theory, the stability of the MPC system was proven. Finally, a dual-loop control (DLC) strategy was used for comparison to verify the superiority of the MPC strategy. The results indicate that compared with the DLC strategy under the gradual braking condition, the root mean square of the front and rear body vertical velocities, body pitch angle, and body pitch angle velocity under the MPC strategy were all reduced by more than $70 \%$, thus improving the ride comfort of the vehicle.
\end{abstract}

Keywords: active suspension; braking intensity; model prediction; stability; equivalent halfvehicle model

\section{Introduction}

Improving the ride comfort of vehicles is crucial to improving driving experience. Suspension is a main component connecting the road and the body of a vehicle and has a significant influence on the ride comfort of the vehicle [1,2]. Vehicle suspensions can be classified into three types: passive suspension, semi-active suspension, and active suspension [3-5]. Compared with passive suspension and semi-active suspension, active suspension can generate active control force to suppress the influence of irregular interference on ride comfort, which will significantly improve the ride comfort of a vehicle [6]. Some car manufacturing companies have used active suspension to suppress vehicle body vibration during driving, such as Volkswagen and Mercedes-Benz [7]. Recently, this research direction has attained significant attention [8-10]. Therefore, research on active suspension control is of great significance.

When a vehicle travels in a straight line, the impact on the vehicle body mainly arises from the vertical input of road surface and the longitudinal movement of the vehicle. Present research is mostly focused on suppressing vehicle body vibration caused by road input [11-13]; some prominent examples include adaptive control [14], robust control [15], sliding mode control [16], and adaptive fuzzy control [17]. These control strategies can be classified into two categories. The first category considers the suspension system as a definite system $[18,19]$. The second category considers the uncertainty of the suspension system caused by changes in the number of passengers and loaded cargo [20,21]. In the first category, a dual-loop control (DLC) is proposed to suppress the vertical movement of the vehicle body caused by road input [22]. For the quarter-vehicle model that simplifies the vehicle vertical motion model to a single-wheel model [23], a sliding mode controller 
was designed to improve the vibration isolation effect of the body [24]. For the 7-degrees-offreedom vehicle model, a backstepping controller was designed [25] and improved the ride comfort of the vehicle. Furthermore, the time-varying hysteresis effect of active suspension actuators is also critical for suspension control. In this regard, a suspension dynamics model with time delay was established, and the $\mathrm{H} \infty$ control strategy was used to effectively suppress the sprung mass acceleration [26]. In the second category, the uncertainty of the suspension system causes a reduction in the suspension control performance. Several intelligent control methods have been used to address this problem [27-29]. An adaptive neural network [30] and adaptive sliding mode control [31] were applied to address the problems caused by body mass and unknown nonlinear functions and thus improved the comfort of the vehicle. Considering the control input delay and unknown nonlinear dynamic active suspension system, a new fuzzy adaptive control strategy was proposed which uses a finite time adaptive algorithm to deal with the parameter error problem [32]. An adaptive actuator failure compensation scheme was proposed to avoid actuator failure and deterioration of the suspension performance [33,34].

The aforementioned studies mainly focused on restraining vehicle body vibration caused by road input. The vertical vibration of the vehicle body caused by the longitudinal movement of the vehicle has been relatively less investigated; vehicles frequently experience the brake process during driving, especially in urban areas [35]. Therefore, it is important to study the suppression strategy of vehicle body vibration caused by braking intensity. The half-vehicle model that simplifies the vehicle vertical motion model to a double-wheel model [23] can reflect the influence of longitudinal motion on vertical motion. Therefore, based on the half-vehicle model, a vehicle model suitable for studying the influence of the braking intensity was established in this study to address the problem of vertical vibration of vehicle caused by the braking intensity. Then, a control strategy to suppress the vertical vibration of a vehicle was proposed. The main contributions of this study are summarized as follows:

- An equivalent half-vehicle model that includes the effect of braking intensity, which can be used to study the effect of braking intensity on vehicle vertical vibration, was established;

- A model predictive control (MPC) strategy was proposed to suppress the vertical movement of a vehicle. Based on Lyapunov's theory, the stability of the MPC system was proved.

The remainder of this paper is structured as follows: the equivalent half-vehicle model is presented in Section 2; the MPC strategy is established and the stability of the MPC system is proven in Section 3; a comparative simulation analysis is provided in Section 4; and the conclusions drawn from the study are summarized in Section 5.

\section{Equivalent Half-Vehicle Model}

Because of the introduction of the impact of braking intensity on the body, the conventional half-vehicle model needs to be modified to obtain the required dynamic model. This section first describes the equivalent half-vehicle model and subsequently derives the equivalent half-vehicle model.

\subsection{Equivalent Half-Vehicle Model Description}

The active suspension of a 4-degrees-of-freedom vehicle can reflect the pitch and vertical movement of the vehicle. Therefore, this type of model is adopted as a base to establish a half-vehicle model that includes the influence of braking intensity. The front and rear wheel loads caused by the braking intensity are transferred to reflect the braking intensity in the half-vehicle model; the effect is equivalent to the front axle equivalent force $F_{m f}$ and the rear axle equivalent force $F_{m r}$ acting on the front and rear suspensions, respectively. The equivalent 4-degrees-of-freedom half-vehicle model, including the influence of braking intensity, is shown in Figure 1. This equivalent half-vehicle model means that the vehicle is running on an ideal road and there is no road input that affects the ride comfort of the 
vehicle. In fact, the road input will have certain undulations which will affect the ride comfort of the vehicle. In order to better understand the effect of braking intensity on ride comfort, an assumption that the vehicle is driving on an ideal road (i.e., road input is zero) is made.

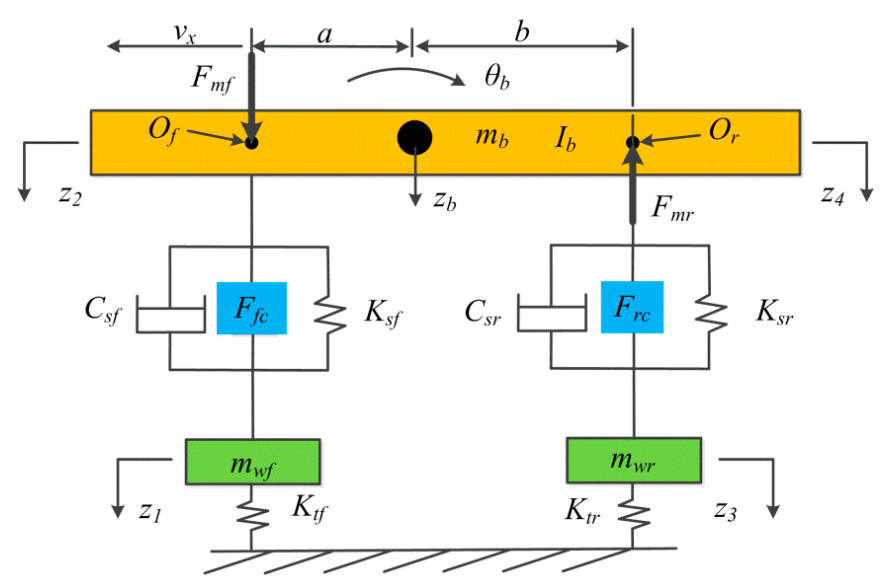

Figure 1. Equivalent half-vehicle model.

In Figure $1, v_{x}$ is the vehicle velocity; $a$ and $b$ are the distances from the mass center of the body to the front and rear axles, respectively; $m_{b}, I_{b}$, and $z_{b}$ are half-body mass, half-body moment of inertia, and half-body mass center position, respectively; $\theta_{b}$ is the pitch angle of the body; $z_{2}$ and $z_{4}$ are the vertical displacements of the front and rear bodies, respectively; $z_{1}$ and $z_{3}$ are the vertical displacements of the front and rear unsprung masses, respectively; $C_{s f}$ and $C_{s r}$ are the front and rear suspension damping, respectively; $K_{s f}$ and $K_{s r}$ are the front and rear suspension stiffnesses, respectively; $F_{f c}$ and $F_{r c}$ are the front and rear suspension control forces, respectively; $K_{t f}$ and $K_{t r}$ are the front and rear tires stiffnesses, respectively; and $m_{w f}$ and $m_{w r}$ are the front and rear unsprung masses, respectively. In addition, in this paper, the vertical motions of $O_{f}$ and $O_{r}$ are called the vertical motion of front and rear bodies, respectively.

\subsection{Equivalent Half-Vehicle Model Derivation}

When the braking intensity is $z$, the front wheel load $F_{z f}$ and rear wheel load $F_{z r}$ are represented as follows:

$$
\left\{\begin{array}{l}
F_{z f}=G\left(b+z h_{g}\right) / L \\
F_{z r}=G\left(a-z h_{g}\right) / L
\end{array}\right.
$$

where $G=\left(m_{b}+m_{w r}+w_{m f}\right) g$ is the half-vehicle gravity ( $g$ is the acceleration of gravity), $L$ is the wheelbase, $L=a+b$, and $h_{g}$ is the height of the body mass center. Here, $G z h_{g} / L$ is the dynamic load, that is, the wheel load transfer caused by the braking strength of the vehicle. According to the effect of braking intensity, ignoring the transfer of the unsprung mass, the dynamic load is equivalent to the front axle equivalent force $F_{m f}$ and the rear axle equivalent force $F_{m r}$, the absolute values of which are:

$$
\left\{\begin{array}{l}
F_{m f}=a b s\left(m_{b} g z h_{g} / L\right) \\
F_{m r}=a b s\left(-m_{b} g z h_{g} / L\right)
\end{array}\right.
$$

Here, $F_{m f}$ and $F_{m r}$ are a pair of force couples caused by the braking intensity. This force couple will affect the movement of the vehicle body. Therefore, the force couple should be considered when controlling the suspension under braking conditions. 
The following is the process of establishing the dynamic model of the vehicle components without considering the influence of gravity. Because the vertical motion of the vehicle is owing to the existence of the suspension and the unsprung mass stiffness, which cancel the effect of gravity (as gravity is also in the vertical direction), there is no need to consider the influence of gravity. The force couple of $F_{m f}$ and $F_{m r}$ is caused by the longitudinal movement of the vehicle and must be considered.

A suspension is a component that connects the body and unsprung mass. The forces generated by the front and rear suspensions are:

$$
\left\{\begin{array}{l}
F_{f}=K_{s f}\left(z_{1}-z_{2}\right)+C_{s f}\left(\dot{z}_{1}-\dot{z}_{2}\right)+F_{f c} \\
F_{r}=K_{s r}\left(z_{3}-z_{4}\right)+C_{s r}\left(\dot{z}_{3}-\dot{z}_{4}\right)+F_{r c}
\end{array}\right.
$$

where $F_{f}$ and $F_{r}$ are the forces generated by the front and rear suspensions, respectively: $\dot{z}_{1}, \dot{z}_{2}, \dot{z}_{3}$, and $\dot{z}_{4}$ are the vertical velocities of the front unsprung mass, front body, rear unsprung mass, and rear body, respectively.

For an unsprung mass, applying Newton's second law, it can be obtained that:

$$
\left\{\begin{array}{l}
m_{w f} \ddot{z}_{1}=-K_{t f} z_{1}-F_{f} \\
m_{w r} \ddot{z}_{3}=-K_{t r} z_{3}-F_{r}
\end{array}\right.
$$

where $\ddot{z}_{1}$ and $\ddot{z}_{3}$ are the vertical accelerations of the front and rear unsprung masses, respectively.

Applying Newton's second law for the vehicle body, it can be obtained that:

$$
m_{b} \ddot{z}_{b}=F_{f}+F_{r}
$$

where $\ddot{z}_{b}$ is the vertical acceleration of the vehicle body mass center.

The dynamic equation for the pitch angle of the vehicle body is:

$$
\begin{aligned}
I_{p} \ddot{\theta}_{b} & =-a F_{f}+b F_{r}-a F_{m f}-b F_{m r} \\
& =-a F_{f}+b F_{r}-m_{b} g z h_{g}
\end{aligned}
$$

where $\ddot{\theta}_{b}$ is the pitch acceleration of the vehicle body.

When the pitch angle is small, it can be obtained that:

$$
\left\{\begin{array}{l}
\ddot{z}_{2}=\ddot{z}_{b}-a \ddot{\theta}_{b} \\
\ddot{z}_{4}=\ddot{z}_{b}+b \ddot{\theta}_{b}
\end{array}\right.
$$

where $\ddot{z}_{2}$ and $\ddot{z}_{4}$ are the vertical accelerations of the front and the rear bodies, respectively.

\section{MPC Strategy}

The vertical motion suppression of a vehicle is a multi-objective control problem, and MPC has the ability to achieve multi-objective optimization. In this section, an MPC strategy is first established, and the stability of the MPC system is proven based on Lyapunov's theory.

The MPC strategy includes the MPC system and equivalent half-vehicle model. The MPC system includes a predictive model and rolling optimization. The basic block diagram of the MPC strategy is shown in Figure 2. 


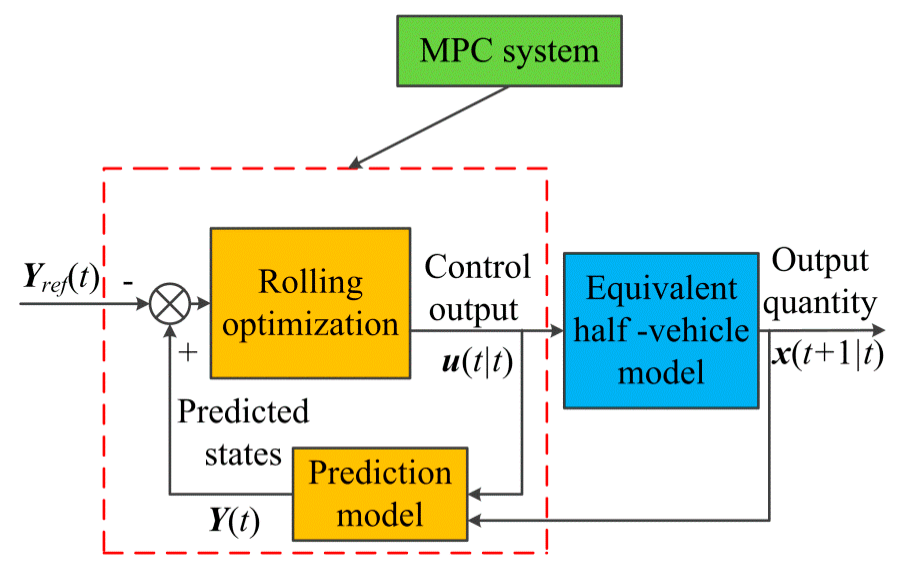

Figure 2. Basic block diagram of the model predictive control (MPC) strategy.

The predictive model is the core part of the MPC strategy, and this is achieved through the equivalent half-vehicle model. The MPC strategy essentially involves obtaining the predicted state $Y(t)$ through the predictive model (where $t$ is the current moment and $i$ is the predicted time step). Furthermore, the difference between $Y(t)$ and the reference state $\boldsymbol{Y}_{\text {ref }}(t)$ in performing rolling optimization through the established objective function to obtain the control output $u(t \mid t)$ is considered, which is used to control the equivalent half-vehicle model. Subsequently, the current control output, $\boldsymbol{u}(t \mid t)$, and the equivalent half-vehicle model output, $x(t+1 \mid t)$, are passed to the prediction model for state prediction. This cycle proceeds back and forth to achieve the rolling optimization control.

\subsection{MPCSsystem}

\subsubsection{Predictive Model}

Combining Equations (2)-(7), a model can be obtained, which is:

$$
\left\{\begin{aligned}
\ddot{z}_{1}= & 1 / m_{w f}\left(-K_{t f} z_{1}-K_{s f}\left(z_{1}-z_{2}\right)-C_{s f}\left(\dot{z}_{1}-\dot{z}_{2}\right)-F_{f c}\right) \\
\ddot{z}_{2}= & \left(1 / m_{b}+a 2 / I_{p}\right)\left(K_{s f}\left(z_{1}-z_{2}\right)+C_{s f}\left(\dot{z}_{1}-\dot{z}_{2}\right)+F_{f c}\right)+ \\
& \left(1 / m_{b}-a b / I_{p}\right)\left(K_{s r}\left(z_{3}-z_{4}\right)+C_{s r}\left(\dot{z}_{3}-\dot{z}_{4}\right)+F_{r c}\right)+a / I_{p} m_{b} g z h_{g} \\
\ddot{z}_{3}= & 1 / m_{w r}\left(-K_{t r} z_{3}-K_{s r}\left(z_{3}-z_{4}\right)-C_{s r}\left(\dot{z}_{3}-\dot{z}_{4}\right)-F_{r c}\right) \\
\ddot{z}_{4}= & \left(1 / m_{b}-a b / I_{p}\right)\left(K_{s f}\left(z_{1}-z_{2}\right)+C_{s f}\left(\dot{z}_{1}-\dot{z}_{2}\right)+F_{f c}\right)+ \\
& \left(1 / m_{b}+b 2 / I_{p}\right)\left(K_{s r}\left(z_{3}-z_{4}\right)+C_{s r}\left(\dot{z}_{3}-\dot{z}_{4}\right)+F_{r c}\right)-b / I_{p} m_{b} g z h_{g}
\end{aligned}\right.
$$

Equation (8) can be written in the form of a differential equation as:

$$
\dot{x}=A x+B u
$$

where $x=\left[\dot{z}_{1}, \dot{z}_{2}, \dot{z}_{3}, \dot{z}_{4}, z_{1}, z_{2}, z_{3}, z_{4}\right]^{\mathrm{T}}$ are the state quantities; $\boldsymbol{u}=\left[z, F_{f c}, F_{r c}\right]^{\mathrm{T}}$ are control outputs; $A$ and $B$ are state matrix and control matrix, respectively. See Appendix A for specific elements. The system is a linear time-invariant system.

Equation (9) expresses the continuous system and. using the first-order Euler method for discretization, becomes:

$$
\frac{d x}{d t} \approx \frac{x(t+1 \mid t)-x(t \mid t)}{T_{S}}
$$

where $T_{S}$ is the sampling time; $x(t \mid t)$ and $x(t+1 \mid t)$ are the states at time $t$ and $t+1$, respectively. The form of $t+i$ in the text refers to the increase in the $i$-th time domain from time $t$. The actual corresponding time is $t+i T_{s}$, where $i=1,2,3,(\ldots)$. 
Combining Equations (9) and (10), a discrete system can be obtained, that is:

$$
\left\{\begin{array}{l}
\boldsymbol{x}(t+1 \mid t)=\boldsymbol{A}_{a} \boldsymbol{x}(t \mid t)+\boldsymbol{B}_{b} \boldsymbol{u}(t \mid t) \\
\boldsymbol{A}_{a}=\boldsymbol{I}_{8 * 8}+\boldsymbol{A} T_{s} \\
\boldsymbol{B}_{b}=\boldsymbol{B} T_{s}
\end{array}\right.
$$

Converting Equation (11) into an equation for controlling the increment and adding the output equation, the state equation of the discrete system is:

$$
\left\{\begin{array}{l}
\boldsymbol{\xi}(t+1 \mid t)=\widetilde{A}_{a} \boldsymbol{\xi}(t \mid t)+\widetilde{\boldsymbol{B}}_{b} \Delta \boldsymbol{u}(t \mid t) \\
\boldsymbol{\eta}(t \mid t)=\widetilde{\boldsymbol{C}}_{c} \boldsymbol{\xi}(t \mid t)
\end{array}\right.
$$

where $\mathcal{\xi}(t \mid t)=[x(t \mid t) ; \boldsymbol{u}(t-1 \mid t)]$ are the augmented state quantities of the system; $\widetilde{A}_{a}=$ $\left[\boldsymbol{A}_{a}, \boldsymbol{B}_{b} ; \mathbf{0}_{3 * 8}, \boldsymbol{I}_{3 * 3}\right] ; \widetilde{\boldsymbol{B}}_{b}=\left[\boldsymbol{B}_{b} ; \boldsymbol{I}_{3 * 3}\right] ;$ Output matrix $\widetilde{\boldsymbol{C}}_{c}=\boldsymbol{I}_{11 * 11}, \boldsymbol{I}$ is the identity matrix; and $\Delta \boldsymbol{u}(t \mid t)=\boldsymbol{u}(t \mid t)-\boldsymbol{u}(t-1 \mid t)$. Here, all augmented state quantities are output.

Let $N p$ and $N c$ be the forecast time domain and control time domain of the system, respectively. The augmented state quantity and system output quantity in the forecast time domain are:

$$
\left\{\begin{aligned}
\boldsymbol{\zeta}(k+N p \mid t)= & \widetilde{\boldsymbol{A}}_{a} \boldsymbol{\xi}(t \mid t)+\widetilde{\boldsymbol{A}}_{a}{ }^{N p-1} \widetilde{\boldsymbol{B}}_{b} \Delta \boldsymbol{u}(t \mid t)+\cdots+\widetilde{\boldsymbol{A}}_{a}{ }^{N p-N c} \widetilde{\boldsymbol{B}}_{b} \Delta \boldsymbol{u}(t+N c \mid t) \\
& +\cdots+\widetilde{\boldsymbol{B}}_{b} \Delta \boldsymbol{u}(t+N p-1 \mid t) \\
\eta(k+N p \mid t)= & \widetilde{\boldsymbol{C}}_{c} \widetilde{\boldsymbol{A}}_{a} \boldsymbol{\xi}(t \mid t)+\widetilde{\boldsymbol{C}}_{c} \widetilde{\boldsymbol{A}}_{a}{ }^{N p-1} \widetilde{\boldsymbol{B}}_{b} \Delta \boldsymbol{u}(t \mid t)+\cdots \\
& +\widetilde{\boldsymbol{C}}_{c} \widetilde{\boldsymbol{A}}_{a}^{N p-N c} \widetilde{\boldsymbol{B}}_{b} \Delta \boldsymbol{u}(t+N c \mid t)+\cdots+\widetilde{\boldsymbol{C}}_{c} \widetilde{\boldsymbol{B}}_{b} \Delta \boldsymbol{u}(t+N p-1 \mid t)
\end{aligned}\right.
$$

Equation (13) can be written in matrix form, that is:

$$
Y(t)=\psi \xi(t \mid t)+\chi \Delta U_{t}
$$

The details on $\boldsymbol{Y}(t), \boldsymbol{\psi}, \boldsymbol{\chi}$, and $\Delta \boldsymbol{U}_{t}$ are provided in Appendix B.

\subsubsection{Rolling Optimization}

Before applying the MPC, the objective function should be selected first. In order to obtain feasible solutions to the optimization objective, a relaxation factor is added to the objective function [36] as follows:

$$
\boldsymbol{J}\left(\xi(t), \boldsymbol{u}(t-1), \Delta \boldsymbol{U}_{t}\right)=\sum_{i=1}^{N p}\left\|\boldsymbol{\eta}(t+\mathrm{i} \mid t)-\boldsymbol{\eta}_{r e f}(t+\mathrm{i} \mid t)\right\|^{2} Q+\sum_{i=0}^{N c-1}\|\Delta \boldsymbol{u}(t+\mathrm{i} \mid t)\|^{2} \boldsymbol{R R}_{\boldsymbol{R}}+\rho \varepsilon^{2}
$$

where $\rho$ is the weight coefficient $(\rho>0)$ and $\varepsilon$ is the relaxation factor. The selection of $Q$ and $\boldsymbol{R} R$ matrices directly affects the control effect. In this study, through simulation experiments, the $\boldsymbol{R} \boldsymbol{R}$ matrix is set as a zero matrix $(\boldsymbol{R} \boldsymbol{R}=$ zeros $(3,3))$ which can obtain a significant control effect. The selection of the $Q$ matrix directly affects the augmented state quantity tracked by the strategy. During the braking process of the vehicle, it is expected to achieve the same vertical velocity as the stationary state-that is, $\left[\dot{z}_{1}, \dot{z}_{2}, \dot{z}_{3}, \dot{z}_{4}\right]=[0,0,0,0]$; therefore, set the output reference $\eta_{\text {ref }}(t+i \mid t)(1: 4,1) \equiv \operatorname{zeros}(4,1)$. The weight matrix $Q$ needs to make the solution of the objective function related only to the first four items of the augmented state. Combining the simulation experiment to determine the $Q$ matrix, $Q \in \mathbf{R}_{11 \times 11}, Q(1,1)=10,000, Q(2,2)=10,000, Q(3,3)=10,000, Q(4,4)=100,000$, and the remaining elements are zero.

Substituting Equation (14) into Equation (15), it can be obtained that:

$$
\boldsymbol{J}\left(\boldsymbol{\xi}(t), \boldsymbol{u}(t-1), \Delta \boldsymbol{U}_{t}\right)=\left[\Delta \boldsymbol{U}_{t}^{\mathrm{T}}, \varepsilon\right] \boldsymbol{H}\left[\Delta \boldsymbol{U}_{t}^{\mathrm{T}}, \varepsilon\right]^{\mathrm{T}}+\boldsymbol{G}_{t}\left[\Delta \boldsymbol{U}_{t}{ }^{\mathrm{T}}, \varepsilon\right]^{\mathrm{T}}+\boldsymbol{P}_{t}
$$


where $\boldsymbol{P}_{t}$ is a constant. A description of $\boldsymbol{H}, \boldsymbol{G}_{t}$, and $\boldsymbol{P}_{t}$ is provided in Appendix C. The problem can be equivalent to the quadratic programming problem, that is:

$$
\begin{aligned}
& \min \left[\Delta \boldsymbol{U}_{t}^{\mathrm{T}}, \varepsilon\right] \boldsymbol{H}_{t}\left[\Delta \boldsymbol{U}_{t}{ }^{\mathrm{T}}, \varepsilon\right]^{\mathrm{T}}+\boldsymbol{G}_{t}\left[\Delta \boldsymbol{U}_{t}{ }^{\mathrm{T}}, \varepsilon\right]^{\mathrm{T}} \\
& \text { s.t } \quad \Delta \boldsymbol{U}_{\min }(k k) \leq \Delta k \boldsymbol{U}_{t}(k k) \leq \Delta \boldsymbol{U}_{\max }(k k), k k=1, \cdots, 3 \mathrm{Nc} \\
& \boldsymbol{Y}_{\min }\left(k k_{1}\right) \leq \boldsymbol{Y}\left(k k_{1}\right) \leq \boldsymbol{Y}_{\max }\left(k k_{1}\right), k k_{1}=1, \cdots, 11 N p \\
& \boldsymbol{U}_{\min }\left(k k_{2}\right) \leq \boldsymbol{u}(t-1 \mid t)\left(k k_{2}\right)+\Delta \boldsymbol{U}_{t}\left(k k_{2}\right) \leq \boldsymbol{U}_{\max }\left(k k_{2}\right), k k_{2}=1,2,3
\end{aligned}
$$

Because the half-vehicle model uses the first control vector of the optimized control sequence, only the first control vector is constrained here-that is, $\boldsymbol{U}_{\min }(2: 3,1)=[-1500$, $-1500], U_{\max }(2: 3,1)=[1500,1500]$-and there is no restriction on other elements of the first control vector.

In this study, the first control quantity (i.e., the braking intensity $z$ ) is treated as interference. This goal can be achieved through constraint restrictions. The specific constraints are:

$$
\left\{\begin{array}{l}
\Delta \boldsymbol{U}_{\min }(1)=[z(t)-z(t-1)] \\
\Delta \boldsymbol{U}_{\max }(1)=[z(t)-z(t-1)]
\end{array}\right.
$$

where $z(t)$ and $z(t-1)$ are the braking intensity at time $t$ and $t-1$, respectively. In other control time domains, the braking intensity increment constraints are all zero.

Regarding the output quantity, only the first four augmented state quantities in the last predicted time domain are restricted, and the rest of the augmented state quantities are not restricted; that is:

$$
\left\{\begin{array}{l}
\boldsymbol{Y}_{\min }(11(N p-1)+1: 11(N p-1)+4,1)=z \operatorname{eros}(4,1) \\
\boldsymbol{Y}_{\max }(11(N p-1)+1: 11(N p-1)+4,1)=\boldsymbol{z} \operatorname{eros}(4,1)
\end{array}\right.
$$

By solving Equation (17), the control output $\boldsymbol{u}(t \mid t)$ can be obtained.

\subsection{Proof of MPC System Stability}

The stability of the MPC system has a significant influence on the control effect. Therefore, it is necessary to prove the stability of the MPC system. Lyapunov's theory is used to prove the stability of the system [37], and the Lyapunov function $V(x(t \mid t))$ is:

$$
\boldsymbol{V}(\boldsymbol{x}(t \mid t))=\sum_{\mathrm{i}=1}^{N p}\left\|\boldsymbol{\eta}(t+\mathrm{i} \mid t)-\boldsymbol{\eta}_{r e f}(t+\mathrm{i} \mid t)\right\|^{2} Q+\sum_{\mathrm{i}=0}^{\mathrm{Nc}-1}\|\Delta \boldsymbol{u}(t+\mathrm{i} \mid t)\|^{2} \boldsymbol{R}+\rho \varepsilon^{2}
$$

Combining the $Q$ matrix and the reference output $\eta_{\text {ref }}(t+i \mid t)(1: 4,1) \equiv z \operatorname{zeros}(4,1)$, it can be known that $V(x(t \mid t))$ is positive definite. The objective function (Equation (15)) always has an optimal solution that satisfies the constraints, and the control increment obtained by its optimization at time $\mathrm{k}$ is $\boldsymbol{\Delta} \boldsymbol{U}_{t}=\boldsymbol{\Delta}[\boldsymbol{u}(t \mid t) ; \boldsymbol{\Delta u}(t+1 \mid t) ; \ldots, \boldsymbol{\Delta u}(t+N c-1 \mid t) ; \ldots ; \boldsymbol{u} \boldsymbol{u}(t+$ $N p-1 \mid t)]$.

At sampling time $t+1$, the Lyapunov function $V(x(t+1 \mid t+1))$ becomes:

$$
\begin{gathered}
\boldsymbol{V}(\boldsymbol{x}(t+1 \mid t+1))=\sum_{\mathrm{i}=1}^{N p}\left\|\boldsymbol{\eta}(t+1+\mathrm{i} \mid t+1)-\boldsymbol{\eta}_{r e f}(t+1+\mathrm{i} \mid t+1)\right\|^{2} Q^{+} \\
\sum_{\mathrm{i}=0}^{\mathrm{Nc}-1}\|\Delta \boldsymbol{u}(t+1+\mathrm{i} \mid t+1)\|^{2} R \boldsymbol{R}+\rho \varepsilon^{2}
\end{gathered}
$$

The control increment obtained by optimization at $k+1$ is $\Delta \boldsymbol{U}_{t+1}=[\boldsymbol{\Delta u}(t+1 \mid t+1)$; $\Delta \boldsymbol{u}(t+1 \mid t+1) ; \ldots, \boldsymbol{\Delta u}(t+N c \mid t+1) ; \ldots ; \boldsymbol{\Delta u}(t+N p \mid t+1)]$.

The connection between the Lyapunov functions $V(x(t \mid t))$ and $V(x(t+1 \mid t+1))$ must be established and the intermediate function $\mathbf{M V}(x(t+1 \mid t+1))$ constructed. The control increment in the intermediate function is $\mathbf{M} \boldsymbol{\Delta} \boldsymbol{U}_{t}=\boldsymbol{\Delta}[\boldsymbol{u}(t+1 \mid t) ; \boldsymbol{\Delta u}(t+2 \mid t) ; \ldots, \boldsymbol{\Delta} \boldsymbol{u}(t+N c$ $\left.-1 \mid t) ; \ldots ; \Delta \boldsymbol{u}(t+N p-1 \mid t) ; \mathbf{0}_{3 \times 1}\right]$. This control increment is directly provided and not 
obtained through optimization. In addition, let $\mathbf{M V}(x(t+1 \mid t+1))$ and the right-hand side of Equation (21) be equal, so:

$$
\boldsymbol{V}(x(t+1 \mid t+1)) \leq \boldsymbol{M V}(x(t+1 \mid t+1))
$$

Therefore,

$$
V(x(t+1 \mid t+1))-V(x(t \mid t)) \leq M V(x(t+1 \mid t+1))-V(x(t \mid t)) .
$$

Combining Equations (13) and (23), it can be obtained that:

$$
\boldsymbol{V}(\boldsymbol{x}(t+1 \mid t+1))-\boldsymbol{V}(\boldsymbol{x}(t \mid t)) \leq\|\boldsymbol{\eta}(t+N p \mid t)\|^{2} Q^{-}\|\boldsymbol{\eta}(t+1 \mid t)\|^{2} Q^{-}\|\Delta \boldsymbol{u}(t \mid t)\|^{2}{ }_{R R}
$$

Since Equation (19) is a constraint on the $\mathrm{Np}$-th prediction vector of the quadratic programming (Equation (17)), it can be obtained that $\eta(t+N p \mid t)(1: 4)=$ zeros $(4,1)$. Combining the $Q$ matrix, it can be obtained that the $\|\boldsymbol{\eta}(t+N p \mid t)\|^{2} Q$ is equal to zero, that is:

$$
\boldsymbol{V}\left(\boldsymbol{x}(t+1 \mid t+1)-\boldsymbol{V}(\boldsymbol{x}(t \mid t)) \leq-\|\boldsymbol{\eta}(t+1 \mid t)\|^{2} Q^{-}\|\Delta \boldsymbol{u}(t \mid t)\|^{2}{ }_{R R} \leq 0\right.
$$

Therefore, the MPC system is stable.

\section{Comparative Simulation Analysis}

Verification of the control strategy through simulation, as carried out in this study, is an important aspect in the development of a control strategy. In this section, the robustness of the MPC system is first discussed, and then the DLC strategy [22] is used as a comparative strategy to verify the superiority of the proposed control strategy. The main technical parameters of the electric vehicle are listed in Table 1.

Table 1. Main technical parameters of the electric vehicle.

\begin{tabular}{ccc}
\hline Project & Parameter & Value \\
\hline \multirow{4}{*}{ Mass and inertia } & Half-body mass $m_{b}(\mathrm{~kg})$ & 846 \\
& Half-body moment inertia $\left.I_{p}(\mathrm{kg \bullet m})^{2}\right)$ & 1516 \\
& Front unsprung mass $m_{w f}(\mathrm{~kg})$ & 47 \\
& Rear unsprung mass $m_{w r}(\mathrm{~kg})$ & 47 \\
\hline \multirow{4}{*}{ Stiffness } & Front suspension stiffness $K_{s f}(\mathrm{~N} / \mathrm{m})$ & 21,000 \\
and damping & Rear suspension stiffness $K_{s r}(\mathrm{~N} / \mathrm{m})$ & 27,300 \\
& Front tire stiffness $K_{t f}(\mathrm{~N} / \mathrm{m})$ & 238,000 \\
& Rear tire stiffness $K_{t r}(\mathrm{~N} / \mathrm{m})$ & 238,000 \\
& Front suspension damping $C_{s f}(\mathrm{~N} \bullet \mathrm{s} / \mathrm{m})$ & 1861 \\
& Rear suspension damping $C_{s r}(\mathrm{~N} \bullet \mathrm{s} / \mathrm{m})$ & 1861 \\
\hline \multirow{4}{*}{ Geometric size } & Distance from the body mass center to the front axle $a(\mathrm{~m})$ & 1.29 \\
& Distance from the body mass center to the rear axle $b(\mathrm{~m})$ & 1.61 \\
& Wheelbase $L(\mathrm{~m})$ & 2.90 \\
& Height of body mass center $h_{g}(\mathrm{~m})$ & 0.82 \\
& Maximum front suspension dynamic deflection $(\mathrm{m})$ & 0.08 \\
\multirow{2}{*}{ Force } & Maximum rear suspension dynamic deflection $(\mathrm{m})$ & 0.08 \\
\hline \multirow{2}{*}{ Control } & Maximum front suspension control force $(\mathrm{N})$ & 1500 \\
parameters & Maximum rear suspension control force $(\mathrm{N})$ & 1500 \\
\hline & Sampling time $T_{s}(\mathrm{~s})$ & 0.02 \\
& Forecast time domain $N p$ & 20 \\
& Control time domain $N c$ & 10 \\
\hline
\end{tabular}


The purpose of the control in this study is to restore the vehicle's vertical direction to a stable state as soon as possible during the braking process. A gradual braking condition [38] is selected as the braking condition, as shown in Figure 3.

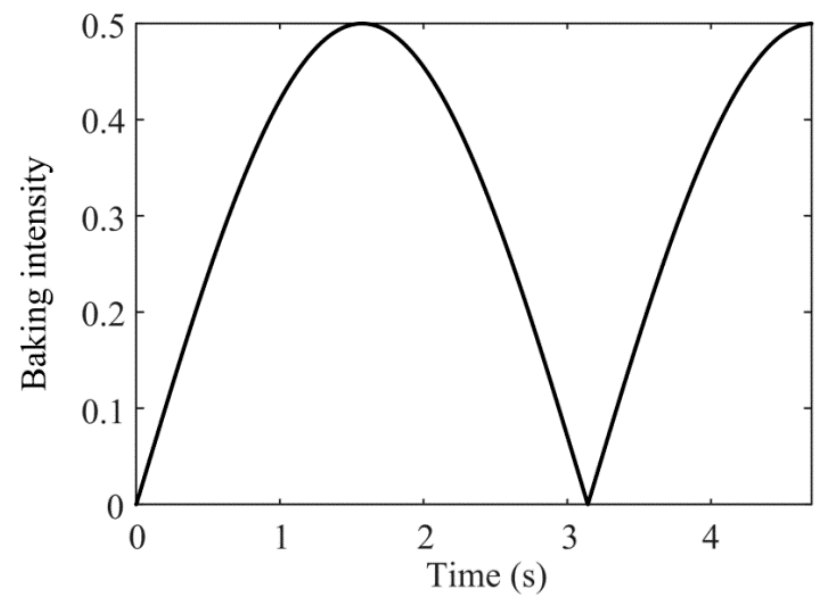

Figure 3. Vehicle braking condition.

The braking condition of the vehicle adopts a gradual form, and its maximum braking intensity is 0.5 . The vehicle was considered to be running on a high-adhesion road to ensure that the vehicle is in a normal braking condition.

\subsection{Robustness Analysis of MPC System}

The stability and robustness of control systems are both research hotspots [39,40]. The stability of the control system has been discussed in Section 3, and the robustness of the control system will be discussed in this section. The robustness of a control system includes its anti-interference ability and the influence of model errors on the performance of the control system [41].

The front body and the rear body vertical velocities are the control targets of this study. When these two state variables interfere, they will have an important influence on the control effect. Therefore, Gaussian noise with a mean value of zero is injected into these two state quantities to verify the anti-interference ability of the control system under the gradual braking condition. The front body and rear body vertical velocity noises are shown in Figure 4a,b, respectively.

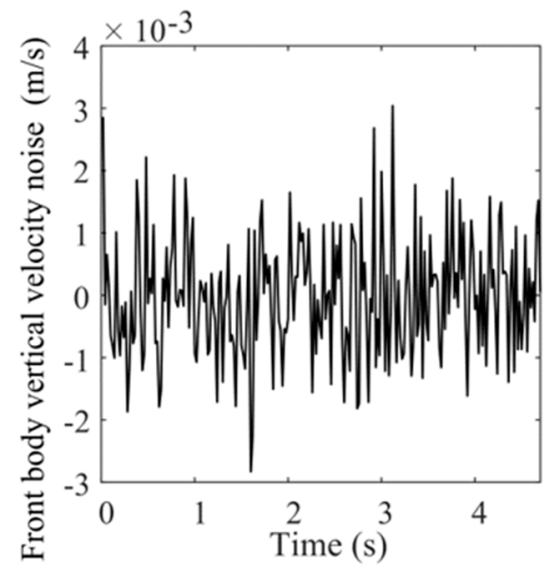

(a)

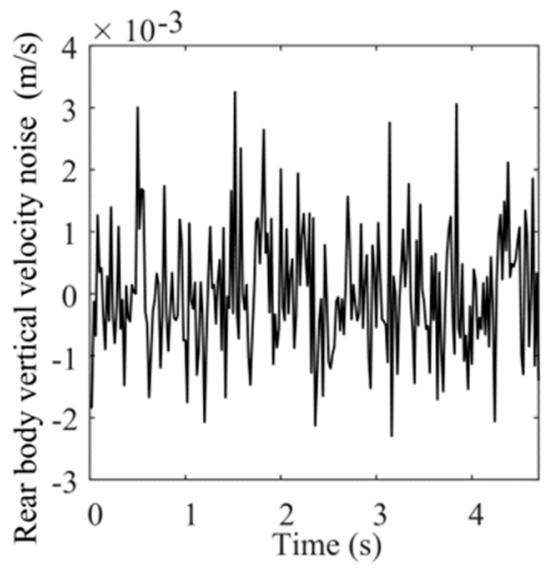

(b)

Figure 4. Body vertical velocity noises. (a) Front body vertical velocity noise; (b) Rear body vertical velocity noise. 
The vertical velocity changes of the front and rear bodies are shown in Figure 5a,b, respectively (no noise and with noise). It can be seen from Figure 5 that although the vertical velocities of the front and rear bodies are inconsistent after the noise is injected, the vertical velocities of the body always fluctuate near the no-noise curves. This verifies that the MPC system has a certain anti-interference ability.

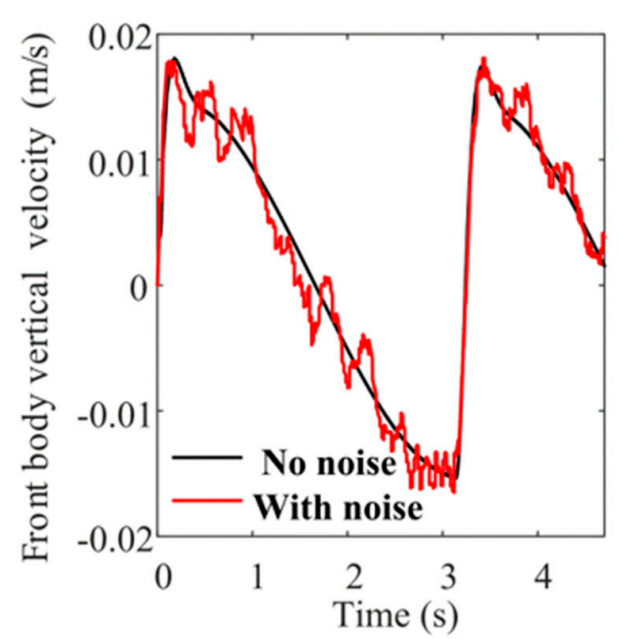

(a)

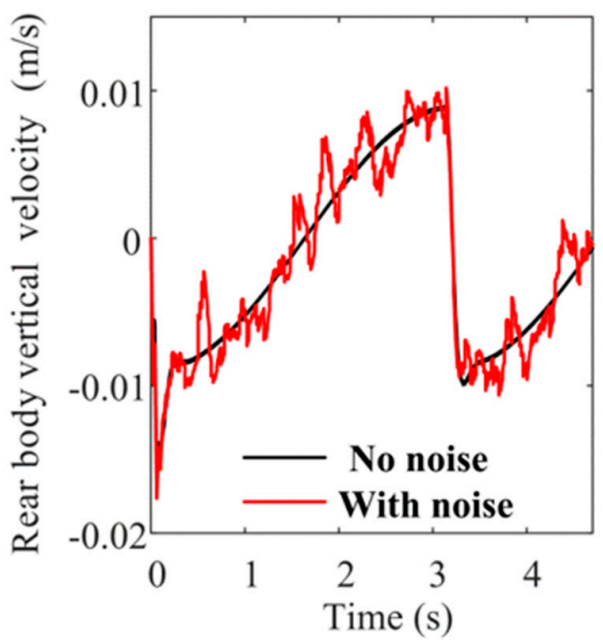

(b)

Figure 5. Body vertical velocity changes. (a) Front body vertical velocity; (b) Rear body vertical velocity.

It should be noted that the rear body vertical velocity, for example, presents an amplitude of around $0.015 \mathrm{~m} / \mathrm{s}$, while the maximum value of noise reaches $0.0033 \mathrm{~m} / \mathrm{s}$. In other words, the maximum noise (i.e., the level of ambient disturbances) accounts for about $22 \%$ of the actual velocity signal, which proves that the proposed control system is able to work under such a challenging working condition.

Stiffness and damping are important parameters of the suspension system. Therefore, the influence of model errors on the performance of the control system is discussed by changing the stiffness and damping of the suspension system in the equivalent half-vehicle model under the gradual braking condition. What needs to be explained here is that the control system still adopts the parameters in Table 1 . The influence of the front and rear stiffness mismatch of the suspension on the control effect is shown in Figure $6 a, b$, respectively.

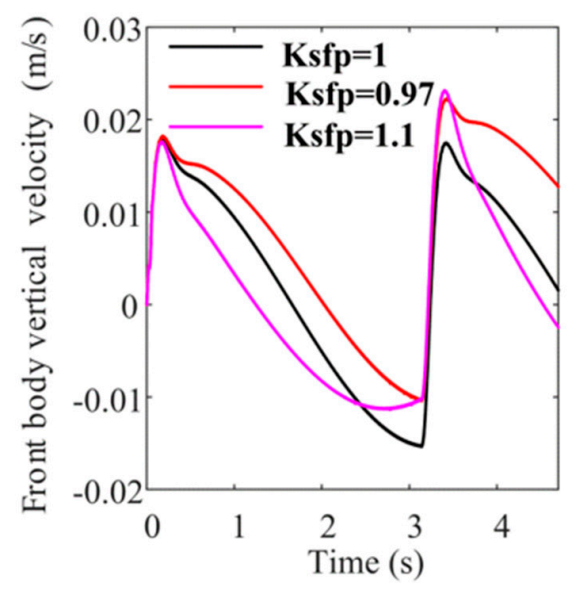

(a)

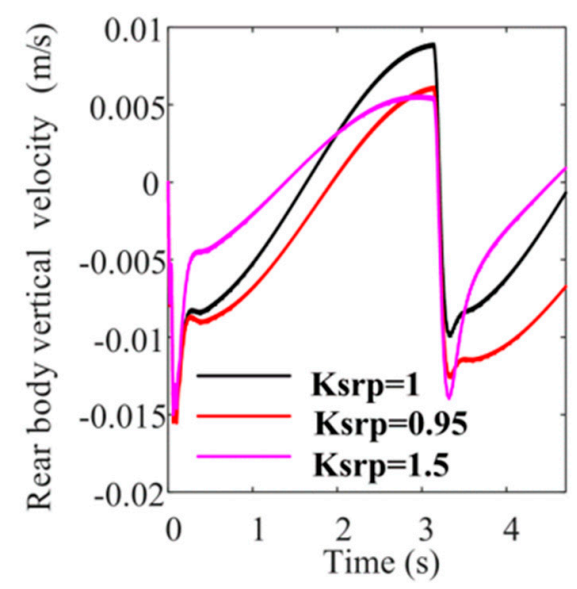

(b)

Figure 6. Suspension stiffness mismatch effect. (a) Front suspension stiffness mismatch effect; (b) Rear suspension stiffness mismatch effect. 
The front suspension stiffness mismatch has an obvious impact on the vertical velocity of the front body, and the rear suspension stiffness mismatch has a remarkable impact on the rear body vertical velocity. Therefore, the vertical velocities of the front and rear bodies are selected to reflect the influence of stiffness parameters' mismatch. The Ksfp and Ksrp in Figure 6 represent the ratios of the actual values in the equivalent half-vehicle model to the corresponding parameters in Table 1. From Figure 6, although simulation results are different for inconsistent model parameters, the trend of change is the same and they all fluctuate around the target value (i.e., zero). Specifically, when Ksfp or Ksrp is less than 1, it has a greater impact on the control effect and the front suspension stiffness has a greater impact on the control effect.

The influence of the front and rear damping mismatch of the suspension on the control effect is shown in Figure 7a,b, respectively. For reasons similar to stiffness, the vertical velocities of the front and rear bodies are selected to reflect the influence of damping parameters' mismatch. The Csfp and Csrp in Figure 7 represent the ratios of the actual values in the equivalent half-vehicle model to the corresponding parameters in Table 1. Similar to the stiffness parameter, when the Csfp or Csrp is lower than 1, it has a greater impact on the control effect, while the front suspension damping parameter has a significant impact on the control effect. Combining Figure 6; Figure 7, it can be seen that the stiffness parameter has a greater impact on the control effect. Overall, Figures 6 and 7 show that the MPC system has a certain ability to tolerate parameter mismatch.

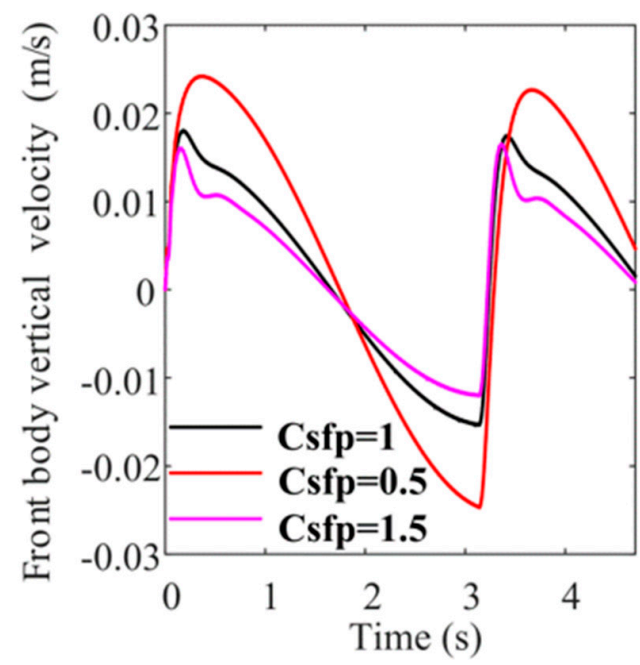

(a)

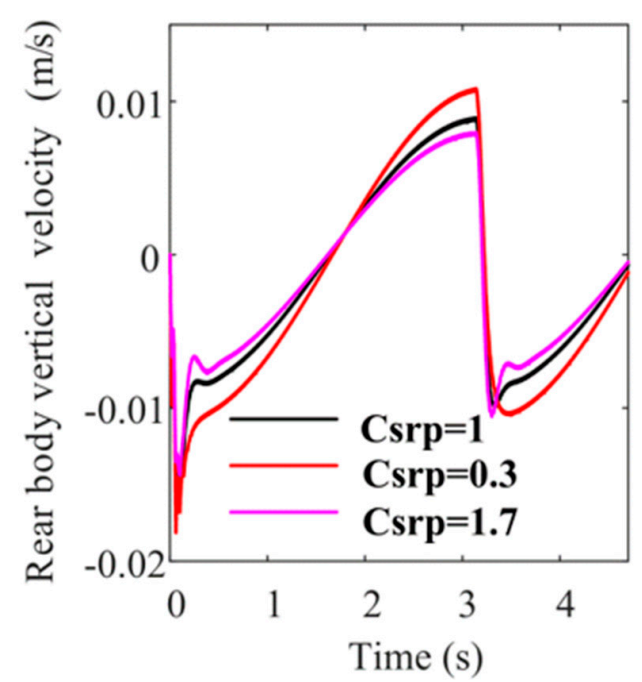

(b)

Figure 7. Suspension damping mismatch effect. (a) Front suspension damping mismatch effect; (b) Rear suspension damping mismatch effect.

Note that in Figures 6 and 7, the coefficients Ksfp, Ksrp, Csfp and Csrp are tuned in such a way that maximum tolerance of model errors is reached, meaning that further increase in the magnitude of these four coefficients would lead to divergence of the control system.

\subsection{Comparative Analysis with DLC}

The changes in vertical velocity of the vehicle body affect vehicle comfort. The changes in the vertical velocity of the front and rear bodies are shown in Figure $8 \mathrm{a}, \mathrm{b}$, respectively. 


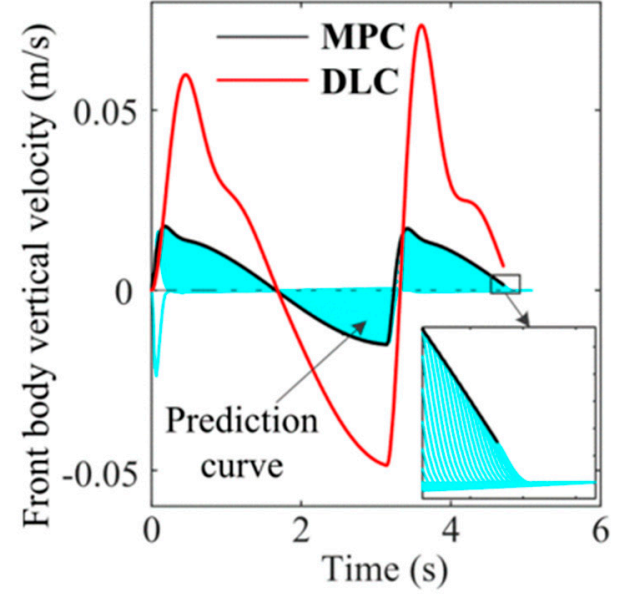

(a)

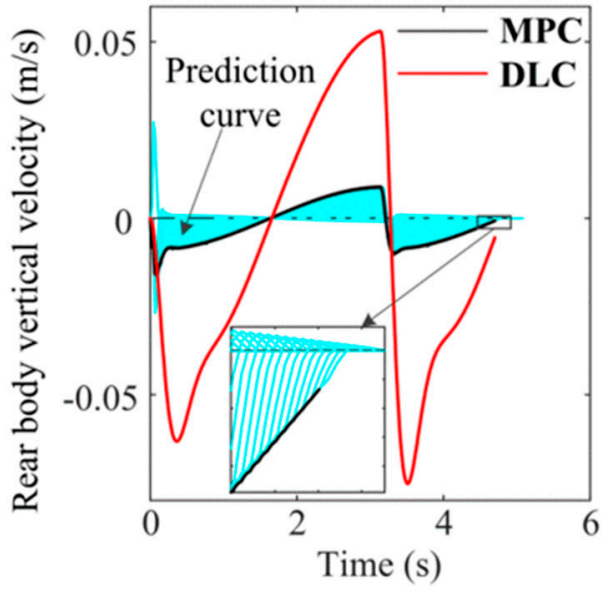

(b)

Figure 8. Changes in the vertical velocity of the vehicle body. (a) Vertical velocity of the front body; (b) Vertical velocity of the rear body.

In Figure 8, the prediction curve refers to the prediction curve obtained by the MPC strategy, and the same applies to the prediction curve in Figure 9. Figure 8a indicates that the absolute values of the maximum front body vertical velocity via the MPC and DLC strategies are 0.0178 and $0.0736 \mathrm{~m} / \mathrm{s}$, respectively. When compared with the DLC strategy, the MPC strategy shows that the absolute value of the maximum front body vertical velocity dropped by $75.82 \%$. Figure $8 \mathrm{~b}$ illustrates that the absolute values of the maximum rear body vertical velocity via the MPC and DLC strategies are 0.0158 and $0.0752 \mathrm{~m} / \mathrm{s}$, respectively. When compared with the DLC strategy, the MPC strategy shows that the absolute value of the maximum rear body vertical velocity dropped by $78.99 \%$. From the enlarged part of Figure 8, the predicted curve is observed to finally stabilize near the zero value.

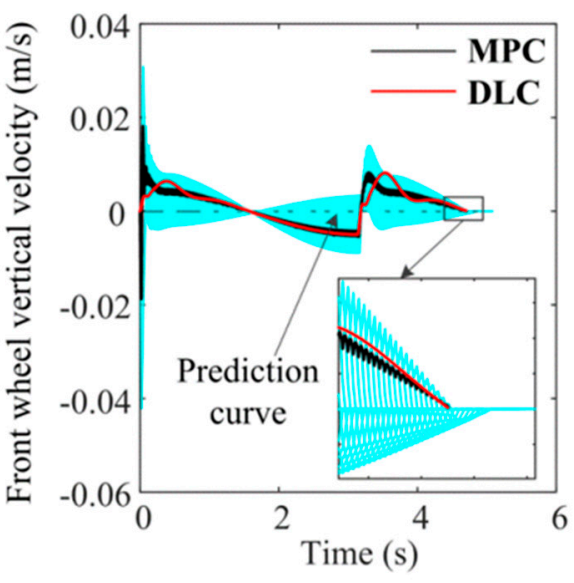

(a)

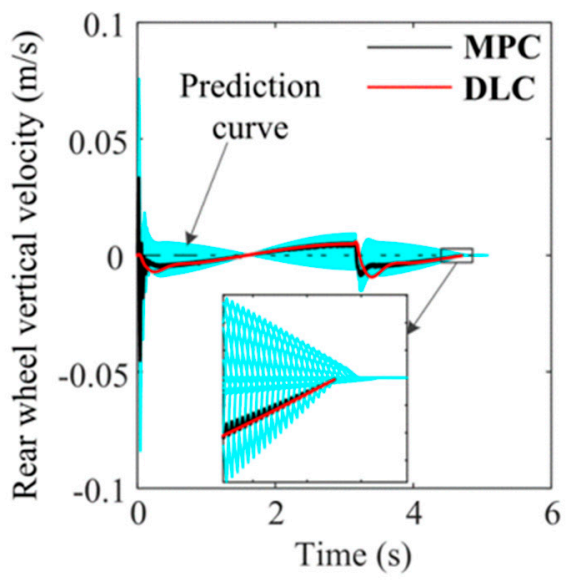

(b)

Figure 9. Changes in the vertical velocity of the wheels. (a) Vertical velocity of the front wheel; (b) Vertical velocity of the rear wheel.

The changes in vertical velocity of the wheels will affect the comfort of the vehicle. The changes in the vertical velocity of the front and rear wheels are shown in Figure 9a,b, respectively. 
Figure 9 indicates that the changes in vertical speed of the wheels under the two control strategies are basically the same, indicating that the MPC strategy can reduce the vertical velocity of the vehicle body when the vertical velocity of the wheels does not change significantly. As can be seen from the enlarged part of Figure 9, the final value of the wheel vertical velocity prediction curve is also near zero, which verifies the stability of the MPC system.

When the dynamic deflection of the suspension exceeds the specified value, the body hits the limit block, and this deteriorates the comfort of the vehicle. Therefore, it is necessary to observe the dynamic deflection of the suspension. The changes in dynamic deflection of the front and rear suspensions are shown in Figure 10a,b, respectively.

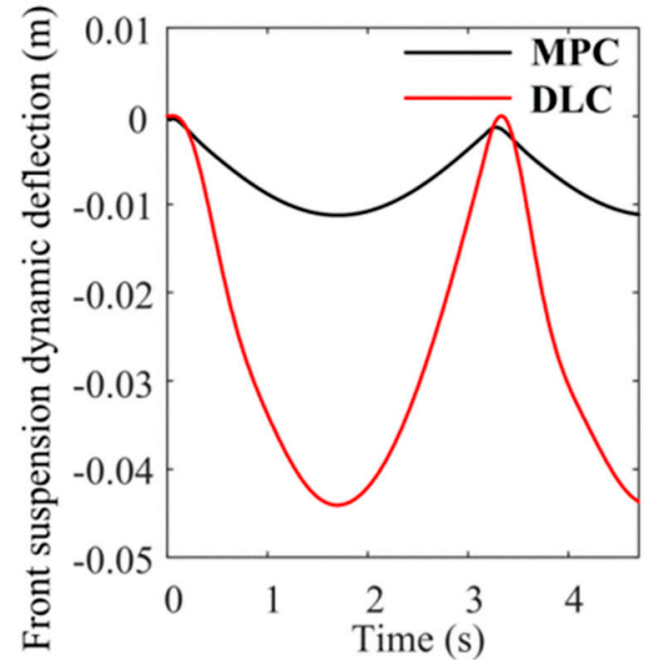

(a)

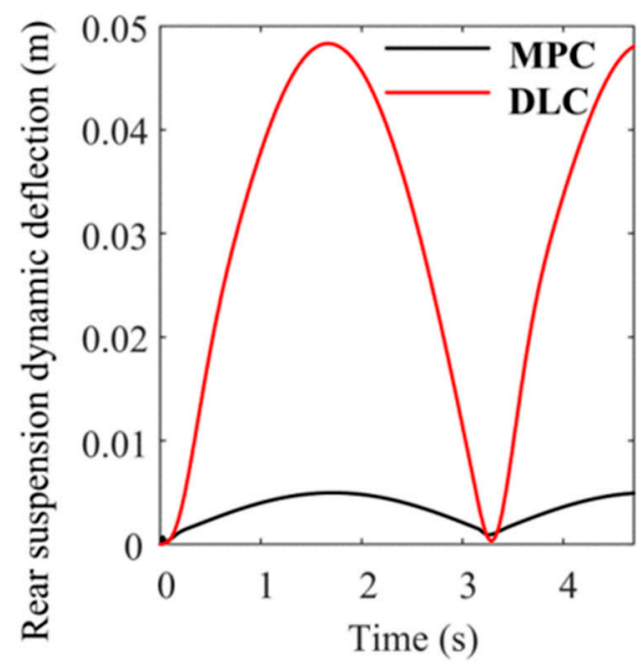

(b)

Figure 10. Suspension dynamic deflection. (a) Front suspension dynamic deflection; (b) Rear suspension dynamic deflection.

From Figure 10a, it can be observed that the absolute values of the maximum front suspension dynamic deflection via the MPC and DLC strategies are 0.0112 and $0.0441 \mathrm{~m}$, respectively. When compared with the DLC strategy, the MPC strategy shows that the absolute value of the maximum front suspension dynamic deflection decreased by $74.60 \%$. Furthermore, as can be observed from Figure 10b, the absolute values of the maximum rear suspension dynamic deflection via the MPC and DLC strategies are 0.0050 and $0.0483 \mathrm{~m}$, respectively. When compared with the DLC strategy, the MPC strategy shows that the absolute value of the maximum rear suspension dynamic deflection dropped by $89.65 \%$. Moreover, Figure 6 shows that the MPC strategy reduces the dynamic deflection of the suspension in most of the cases.

The change in the pitch angle of the vehicle body will affect the driver's field of vision. The changes in the pitch angle and pitch angle velocity of the vehicle body are shown in Figure $11 \mathrm{a}, \mathrm{b}$, respectively. 


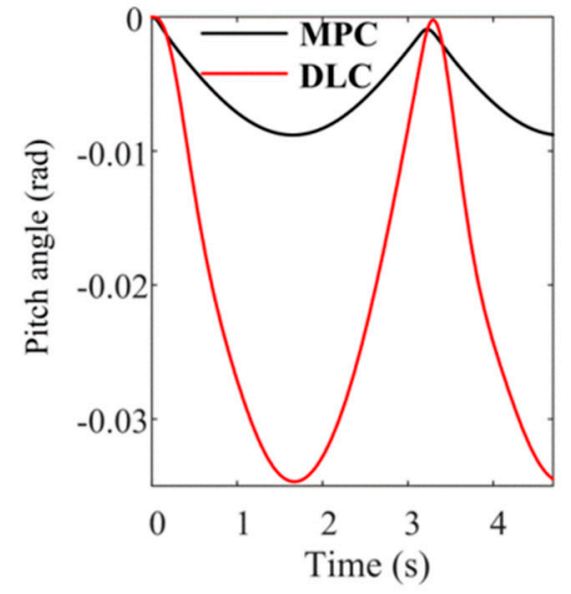

(a)

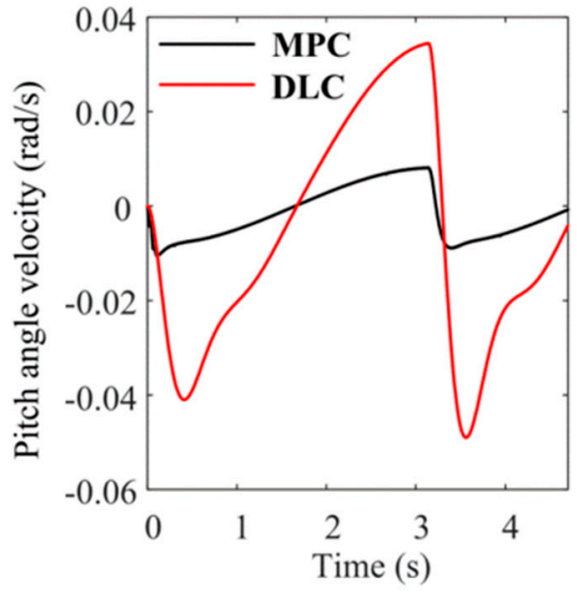

(b)

Figure 11. Body pitch angle and pitch angle velocity. (a) Body pitch angle; (b) Body pitch angle velocity.

As can be observed from Figure 11a, the absolute values of the maximum body pitch angle via the MPC and DLC strategies are 0.0088 and $0.0347 \mathrm{rad}$, respectively. When compared with the DLC strategy, the MPC strategy shows that the absolute value of the maximum body pitch angle dropped by $74.64 \%$. Similarly, as seen in Figure $11 \mathrm{~b}$, the absolute values of the maximum body pitch angle velocity via the MPC and DLC strategies are 0.0105 and $0.0490 \mathrm{rad} / \mathrm{s}$, respectively. Furthermore, when compared with the DLC strategy, the MPC strategy shows that the absolute value of the maximum body pitch angle velocity dropped by $78.57 \%$. The MPC strategy reduces the pitch angle and pitch angle velocity of the body in most of the cases.

The vertical movement of the vehicle body is also an important factor affecting the comfort of the vehicle. The changes in the vertical velocity and vertical acceleration of the vehicle body mass center are shown in Figure 12a,b, respectively.

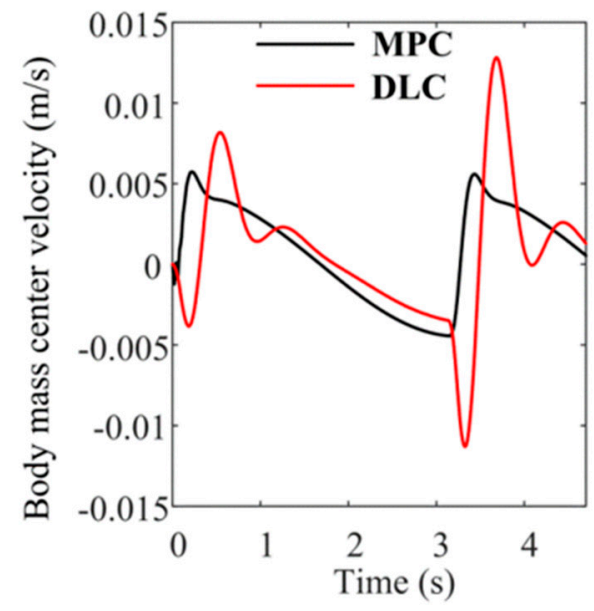

(a)

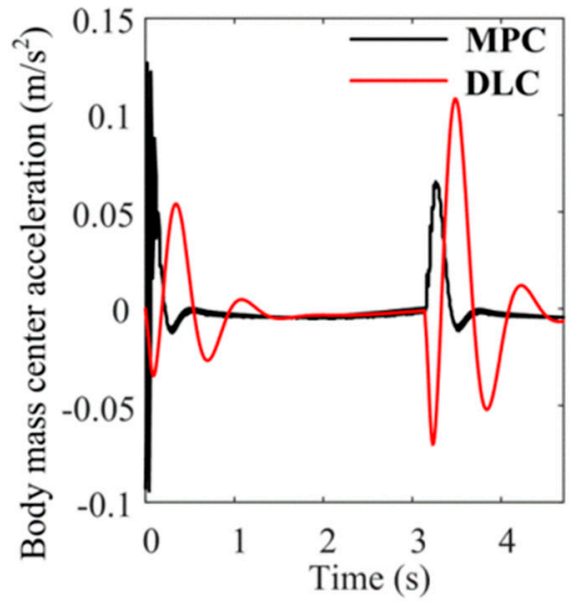

(b)

Figure 12. Body mass center velocity and acceleration. (a) Body mass center velocity; (b) Body mass center acceleration.

It is evident from Figure 12a that the absolute values of the maximum body mass center velocity through the MPC and DLC strategies are 0.0057 and $0.0128 \mathrm{~m} / \mathrm{s}$, respectively. Furthermore, when compared with the DLC strategy, the MPC strategy shows that the absolute value of the maximum body mass center velocity dropped by $55.47 \%$. From Figure 12b, it can be seen that the absolute values of the body mass center accelera- 
tion obtained by the MPC strategy are lower than those obtained by the DLC strategy in most circumstances.

During active suspension control, the maximum control force cannot exceed the maximum action force. The variations in the front and rear suspension control forces are shown in Figure 13a,b, respectively.

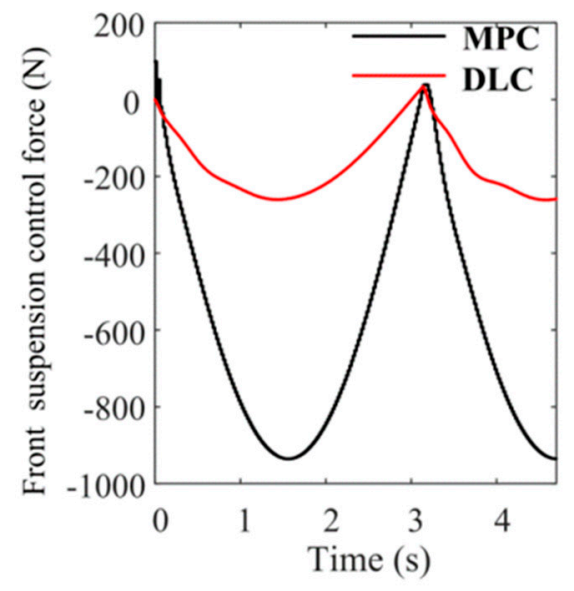

(a)

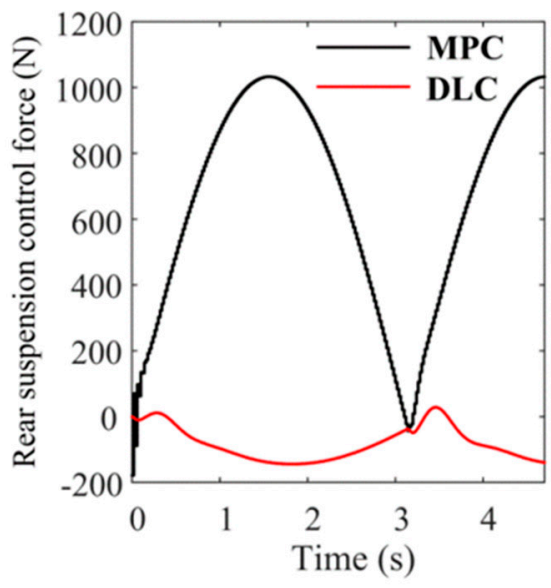

(b)

Figure 13. Front and rear suspension control forces. (a) Front suspension control force; (b) Rear suspension control force.

Figure 13 indicates that under the MPC strategy, the absolute values of the maximum control forces of the front and rear suspensions are 936 and $1033 \mathrm{~N}$, respectively, which do not exceed the constraint value (1500 N). Combining Figures 3 and 8, it can be seen that in order to reduce the vertical motion of the vehicle body caused by the braking intensity, the MPC strategy has greater control force than the DLC strategy for a long time.

The root mean square (RMS) value is an important indicator of signal power. The RMS values of some indicators reflecting the comfort of the vehicle are shown in Table 2. Here, $\omega=(\operatorname{RMS}(\mathrm{DLC})-\mathrm{RMS}(\mathrm{MPC})) / \mathrm{RMS}(\mathrm{DLC})$.

Table 2. Root mean square (RMS) of some parameters.

\begin{tabular}{cccc}
\hline Category & MPC & DLC & \multirow{\omega}{*}{ Parameter } \\
\cline { 1 - 1 } Front body vertical velocity & 0.0107 & 0.0358 & 0.7011 \\
Rear body vertical velocity & 0.0065 & 0.0385 & 0.8312 \\
Body mass center velocity & 0.0032 & 0.0044 & 0.2727 \\
Body mass center acceleration & 0.0163 & 0.0282 & 0.4220 \\
Body pitch angle & 0.0063 & 0.0239 & 0.7364 \\
Body pitch angle velocity & 0.0058 & 0.0251 & 0.7689 \\
\hline
\end{tabular}

From Table 2, it can be seen that the RMS values obtained by the MPC strategy are all smaller than those obtained by the DLC strategy. Compared with the DLC strategy, the RMS values of the front and rear body vertical velocity, body pitch angle and body pitch angle velocity under the MPC strategy are all reduced by more than $70 \%$, further verifying that the MPC strategy improves the comfort of the vehicle.

In summary, under the gradual braking condition, the robustness of the control system is discussed, and two control strategy simulations, namely the MPC and DLC strategies, were carried out. Figure 5 demonstrates that the control system has a certain anti-interference ability. Figures 6 and 7 reflect the influence of parameter mismatch on the control effect, indicating that the control system has a certain tolerance for parameter mismatch. The variations in the vertical velocity of the front and rear bodies are shown 
in Figure $8 \mathrm{a}, \mathrm{b}$, respectively. The absolute values of the vehicle body vertical velocity obtained by the MPC strategy were, in most of the cases, lower than those obtained by the DLC strategy. The prediction curve is finally stable near the zero value. The changes in the vertical velocity of the front and rear wheels are shown in Figure 9a,b, respectively. The changes in the vertical velocity of the wheels under the two control strategies are basically the same, and the final values of the wheel vertical velocity prediction curve are also near the zero value. The dynamic deflection changes of the front and rear suspensions are shown in Figure 10a,b, respectively. Compared with the DLC strategy, the absolute values of the front and rear maximum suspension dynamic deflections obtained by the MPC strategy decreased by more than $74 \%$. The changes in the pitch angle and pitch angle velocity of the vehicle body are shown in Figure 11a,b, respectively. Compared with the DLC strategy, the absolute values of the maximum pitch angle and pitch angle velocity of the vehicle body obtained by the MPC strategy decreased by more than $74.6 \%$. Similarly, the changes in the vertical velocity and vertical acceleration of the body mass center are shown in Figure 12a,b, respectively. The absolute values of the vertical velocity and acceleration of the body under the MPC strategy were lower than those under the DLC strategy in most of the cases. Further, the changes in the front and rear suspension control forces are shown in Figure 13a,b, respectively. The suspension control force under the two control strategies did not exceed the specified values. Moreover, Table 2 shows the RMS of some parameters and compares the two strategies to verify that the MPC strategy improves the comfort of the vehicle.

\section{Conclusions}

Active suspension control technology is key to improving the comfort of vehicles, and research in this regard is, therefore, of great significance. Thus far, studies on active suspension control have mainly focused on vehicle comfort under road input conditions; the impact of braking intensity on vehicle comfort is relatively less investigated. Considering the effect of braking intensity on the vertical movement of the vehicle during braking, an equivalent half-vehicle model based on the axle load transfer relationship was established in this study. Adopting the quadratic optimization method, an MPC strategy in which the control targets are the vertical velocities of front wheel, front body, rear wheel, and rear body to suppress the vertical movement of the vehicle was proposed. The stability of the MPC system was proven based on Lyapunov's theory. Finally, the robustness of the control system was discussed through simulation, and the MPC strategy was compared with the DLC strategy under gradual braking conditions. The results show that the control system has a certain anti-interference ability and parameter mismatch tolerance. Furthermore, the front and rear body vertical velocities and the RMS of the body pitch angle and pitch angle velocity obtained through the MPC strategy were all reduced by more than $70 \%$, improving the comfort of the vehicle. The prediction curves for front wheel, front body, rear wheel, and rear body vertical velocities were all finally stabilized near zero, thus verifying the stability of the MPC system. From this study, MPC strategy can improve the ride comfort deterioration caused by braking strength, and the equivalent half-vehicle model is effective for vehicle control. In this study, only the impact of braking intensity on the ride comfort of the vehicle is considered. In future studies, the impact of braking intensity and road input on the ride comfort of the vehicle can be considered simultaneously.

Author Contributions: J.Z. (Junjiang Zhang) designed the process of control strategy and the performance simulation method, completed the verification of the strategy, dealt with the simulation data, and wrote the first draft of the manuscript. Y.Y., M.H., C.F. and J.Z. (Jun Zhai) provided insights and additional ideas on presentation. All authors have read and agreed to the published version of the manuscript.

Funding: This research was supported by the National Key R\&D Program of China (Grant No. 2018YFB0106100). 
Conflicts of Interest: The authors declare no conflict of interest.

Appendix A

$$
\begin{aligned}
& \boldsymbol{A}=\left[\begin{array}{cccc}
-C_{s f} / m_{w f}, & C_{s f} / m_{w f}, & 0, & 0, \\
-\left(K_{t f}+K_{s f}\right) / m_{w f}, & K_{s f} / m_{w f}, & 0, & 0 ; \\
\left(1 / m_{b}+a 2 / I_{p}\right) C_{s f}, & -\left(1 / m_{b}+a 2 / I_{p}\right) C_{s f}, & \left(1 / m_{b}-a b / I_{p}\right) C_{s r}, & -\left(1 / m_{b}-a b / I_{p}\right) C_{s r}, \\
\left(1 / m_{b}+a 2 / I_{p}\right) K_{s f}, & -\left(1 / m_{b}+a 2 / I_{p}\right) K_{s f}, & \left(1 / m_{b}-a b / I_{p}\right) K_{s r}, & -\left(1 / m_{b}-a b / I_{p}\right) K_{s r} ; \\
0, & 0, & -C_{s r} / m_{w r}, & C_{s r} / m_{w r}, \\
0, & 0, & -\left(K_{t r}+K_{s r}\right) / m_{w r}, & K_{s r} / m_{w r} ; \\
\left(1 / m_{b}-a b / I_{p}\right) C_{s f}, & -\left(1 / m_{b}-a b / I_{p}\right) C_{s f}, & \left(1 / m_{b}+b 2 / I_{p}\right) C_{s r}, & -\left(1 / m_{b}+b 2 / I_{p}\right) C_{s r}, \\
\left(1 / m_{b}-a b / I_{p}\right) K_{s f}, & -\left(1 / m_{b}-a b / I_{p}\right) K_{s f}, & \left(1 / m_{b}+b 2 / I_{p}\right) K_{s r}, & -\left(1 / m_{b}+b 2 / I_{p}\right) K_{s r} ; \\
& 0 & 0_{4 * 4}, & I_{4 * 4} ;
\end{array}\right] \\
& \boldsymbol{B}=\left[\begin{array}{ccc}
0 & 1 / m_{w f} & 0 \\
a m_{b} g h_{g} / I_{p} & 1 / m_{b}+\hat{a} 2 / I_{p} & 1 / m_{b}-a b / I_{p} \\
0 & 0 & -1 / m_{w r} \\
b m_{b} g h_{g} / I_{p} & 1 / m_{b}-a b / I_{p} & 1 / m_{b}+b 2 / I_{p} \\
0_{4 * 4} &
\end{array}\right]
\end{aligned}
$$

Appendix B

$$
\begin{aligned}
& \boldsymbol{Y}(t)=[\boldsymbol{\eta}(t+1 \mid t) ; \boldsymbol{\eta}(t+2 \mid t) ; \cdots ; \boldsymbol{\eta}(t+N p \mid t)] \\
& \psi=\left[\widetilde{\boldsymbol{C}}_{\mathrm{c}} \widetilde{\boldsymbol{A}}_{\mathrm{a}} ; \widetilde{\boldsymbol{C}}_{\mathrm{c}} \widetilde{A}_{\mathrm{a}} 2 ; \cdots ; \widetilde{\boldsymbol{C}}_{\mathrm{c}} \widetilde{A}_{\mathrm{a}}{ }^{\top} N p\right] \\
& \chi=\left[\begin{array}{cccc}
\widetilde{\boldsymbol{C}}_{\mathrm{c}} \widetilde{\boldsymbol{B}}_{\mathrm{b}} & 0 & 0 & 0 \\
\widetilde{\boldsymbol{C}}_{\mathrm{c}} \widetilde{\boldsymbol{A}}_{\mathrm{a}} \widetilde{\boldsymbol{B}}_{\mathrm{b}} & \widetilde{\boldsymbol{C}}_{\mathrm{c}} \widetilde{\boldsymbol{B}}_{\mathrm{b}} & 0 & 0 \\
\vdots & \vdots & \ddots & \vdots \\
\widetilde{\boldsymbol{C}}_{\mathrm{c}} \widetilde{\boldsymbol{A}}_{\mathrm{a}}{ }^{\mathrm{Nc}-1} \widetilde{\boldsymbol{B}}_{\mathrm{b}} & \widetilde{\boldsymbol{C}}_{\mathrm{c}} \widetilde{\boldsymbol{A}}_{\mathrm{a}}^{\mathrm{Nc}-2} \widetilde{\boldsymbol{B}}_{\mathrm{b}} & \cdots & \widetilde{\boldsymbol{C}}_{\mathrm{c}} \widetilde{\boldsymbol{B}}_{\mathrm{b}} \\
\widetilde{\boldsymbol{C}}_{\mathrm{c}} \widetilde{\boldsymbol{A}}_{\mathrm{a}}{ }^{\mathrm{Nc}} \widetilde{\boldsymbol{B}}_{\mathrm{b}} & \widetilde{\boldsymbol{C}}_{\mathrm{c}} \widetilde{A}_{\mathrm{a}}{ }^{N c-1} \widetilde{\boldsymbol{B}}_{\mathrm{b}} & \cdots & \widetilde{\boldsymbol{C}}_{\mathrm{c}} \widetilde{\boldsymbol{A}}_{\mathrm{a}} \widetilde{\boldsymbol{B}}_{\mathrm{b}} \\
\vdots & \vdots & \ddots & \vdots \\
\widetilde{\boldsymbol{C}}_{\mathrm{c}} \widetilde{\boldsymbol{A}}_{\mathrm{a}}{ }^{N p-1} \widetilde{\boldsymbol{B}}_{\mathrm{b}} & \widetilde{\boldsymbol{C}}_{\mathrm{c}} \widetilde{\boldsymbol{A}}_{\mathrm{a}}{ }^{N p-1} \widetilde{\boldsymbol{B}}_{\mathrm{b}} & \cdots & \widetilde{\boldsymbol{C}}_{\mathrm{c}} \widetilde{\boldsymbol{A}}_{\mathrm{a}}{ }^{N p-{ }^{N} \widetilde{\boldsymbol{B}}_{\mathrm{b}}}
\end{array}\right] \\
& \Delta \boldsymbol{U}_{t}=[\Delta \boldsymbol{u}(t \mid t) ; \Delta \boldsymbol{u}(t+1 \mid t) ; \cdots ; \Delta \boldsymbol{u}(t+\mathrm{Nc}-1 \mid t)]
\end{aligned}
$$

\section{Appendix C}

$$
\operatorname{Re}=z \operatorname{eros}(3 N c, 3 N c)
$$

$Q_{e}=I_{N p \times N p} \otimes Q \otimes$ is the Kronecker product

$$
\begin{gathered}
\boldsymbol{E}(t)=\boldsymbol{\psi} \boldsymbol{\xi}(t \mid t)-\boldsymbol{Y}_{r e f}(t) \\
\boldsymbol{Y}_{r e f}(t)=\left[\boldsymbol{\eta}_{r e f}(t+1 \mid t) ; \boldsymbol{\eta}_{r e f}(t+2 \mid t) ; \cdots ; \boldsymbol{\eta}_{r e f}(t+N p \mid t)\right] \\
\boldsymbol{H}=\left[\begin{array}{cc}
\boldsymbol{\psi}^{\mathrm{T}} \boldsymbol{Q}_{\mathrm{e}} \boldsymbol{\psi}+\boldsymbol{R}_{\mathrm{e}} & 0 \\
0 & \rho
\end{array}\right] \\
\boldsymbol{G}_{t}=\left[2 \boldsymbol{E}(t)^{\mathrm{T}} \boldsymbol{Q}_{\mathrm{e}} \boldsymbol{\psi}, 0\right]
\end{gathered}
$$




$$
\boldsymbol{P}_{t}=\boldsymbol{E}(t)^{\mathrm{T}} \boldsymbol{Q}_{\mathrm{e}} \boldsymbol{E}(t)
$$

\section{References}

1. Karim, A.K.; Javadi, A.; Jahed-Motlagh, M.R.; Robust, H. $\infty$ control of an active suspension system with actuator time delay by predictor feedback. IET Control. Theory Appl. 2018, 12, 1012-1023. [CrossRef]

2. Kumar, V.; Rana, K.P.S.; Kumar, J.; Mishra, P. Self-tuned robust fractional order fuzzy PD controller for uncertain and nonlinear active suspension system. Neural. Comput. Appl. 2018, 30, 1827-1843. [CrossRef]

3. Junqiang, Z.; Haibo, G.; Baofeng, Y.; Zhen, L.; Haitao, Y.; Zongquan, D. Design and terramechanics analysis of a Mars rover utilising active suspension. Mech. Mach. Theory 2018, 128, 125-149.

4. Liu, W.; Wang, R.; Ding, R.; Meng, X.; Yang, L. On-line estimation of road profile in semi-active suspension based on unsprung mass acceleration. Mech. Syst. Signal Process. 2020, 135, 1-17. [CrossRef]

5. Hisham, M.S.; Khaled, E.; Mostafa, S. Invariant sets in saturated and robust vehicle suspension control. Arab. J. Sci. Eng. 2020, 45, 7055-7064.

6. Li, P.; Lam, J.; Cheung, K.C. Motion-based active disturbance rejection control for a non-linear full-car suspension system. Proc. Inst. Mech. Eng. Part D Int. J. Automot. Eng. 2018, 232, 616-631. [CrossRef]

7. Tang, G.Y.; Lin, H.; Su, H. Decoupling vibration control for active suspension systems. In Proceedings of the 29th Chinese Control and Decision Conference (CCDC), Chongqing, China, 28-30 May 2017.

8. Shahid, Y.; Minxiang, W. Comparative analysis of different model-based controllers using active vehicle suspension system. Algorithms 2019, 13, 10. [CrossRef]

9. Liu, X.; Pang, H.; Shang, Y. An observer-based active fault tolerant controller for vehicle suspension system. Appl. Sci. 2018, 8, 2568. [CrossRef]

10. Wu, H.; Zheng, L.; Li, Y.; Zhang, Z.; Yu, Y. Robust control for active suspension of hub-driven electric vehicles subject to in-wheel motor magnetic force oscillation. Appl. Sci. 2020, 10, 3929. [CrossRef]

11. Zhou, C.; Liu, X.; Chen, W.; Xu, F.; Cao, B. Optimal sliding mode control for an active suspension system based on a genetic algorithm. Algorithms 2018, 11, 205. [CrossRef]

12. Attia, T.; Vamvoudakis, K.G.; Kochersberger, K. Simultaneous dynamic system estimation and optimal control of vehicle active suspension. Veh. Syst. Dyn. 2019, 57, 1467-1493. [CrossRef]

13. Soh, M.; Jang, H.; Park, J.; Sohn, Y.; Park, K. Development of preview active suspension control system and performance limit analysis by trajectory optimization. Int. J. Automot. Technol. 2018, 19, 1001-1012. [CrossRef]

14. Hua, C.; Chen, J.; Li, Y.; Li, L. Adaptive prescribed performance control of half-car active suspension system with unknown dead-zone input. Mech. Syst. Signal Process. 2018, 111, 135-148. [CrossRef]

15. Guan, Y.; Han, Q.L.; Yao, H.; Ge, X. Robust event-triggered $\mathrm{H} \infty$ controller design for vehicle active suspension systems. Nonlinear Dyn. 2018, 94, 627-638. [CrossRef]

16. Yang, C.; Xia, J.; Park, J.H.; Shen, H.; Wang, J. Sliding mode control for uncertain active vehicle suspension systems: An eventtriggered $\mathrm{H} \infty$ control scheme. Nonlinear Dyn. 2020, 1-13.

17. Min, X.; Li, Y.; Tong, S. Adaptive fuzzy output feedback inverse optimal control for vehicle active suspension systems. Neurocomputing 2020, 403, 257-267. [CrossRef]

18. Kim, H.J.; Yang, H.S.; Park, Y.P. Improving the vehicle performance with active suspension using road-sensing algorithm Comput Struct. 2002, 80, 1569-1577. [CrossRef]

19. Sun, W.; Zhao, Y.; Li, J.; Zhang, L.; Gao, H. Active suspension control with frequency band constraints and actuator input delay. IEEE Trans. Ind. Electron. 2011, 59, 530-537.

20. Du, M.; Zhao, D.; Yang, B.; Wang, L. Terminal sliding mode control for full vehicle active suspension systems. J. Mech. Sci. Technol. 2018, 32, 2851-2866. [CrossRef]

21. Zheng, X.; Zhang, H.; Yan, H.; Yang, F.; Wang, Z.; Vlacic, L. Active full-vehicle suspension control via cloud-aided adaptive backstepping approach. IEEE Trans. Ind. Electron. 2020, 50, 3113-3124. [CrossRef]

22. Fang, Z.; Shu, W.; Du, D.; Xiang, B.; He, Q.; He, K. Semi-active suspension of a full-vehicle model based on double-loop control. Procedia Eng. 2011, 16, 428-437. [CrossRef]

23. Yu, F.; Lin, Y. Automotive System Dynamics, 2rd ed.; Song, X., Li, R., Eds.; China Machine Press: Beijing, China, 2016; pp. 187-196, ISBN 978-7-111-55173-7.

24. Yoshimura, T.; Kume, A.; Kurimoto, M.; Hino, J. Construction of an active suspension system of a quarter car model using the concept of sliding mode control. J. Sound Vib. 2001, 239, 187-199. [CrossRef]

25. Yagiz, N.; Hacioglu, Y. Backstepping control of a vehicle with active suspensions. Control Eng. Pract. 2008, 16, 1457-1467. [CrossRef]

26. Ji, R.; Fang, M.; Li, P.; Yan, G. Theoretical and Experimental Research on H $\infty$ Control Suspension System with Time Delay. Automot. Eng. Int. 2020, 42, 339-344, 352.

27. Lu, R.; Xu, Y.; Zhang, R. A new design of model predictive tracking control for networked control system under random packet loss and uncertainties. IEEE Trans. Ind. Electron. 2016, 63, 6999-7007. [CrossRef] 
28. Pan, H.; Sun, W.; Jing, X.; Gao, H.; Yao, J. Adaptive tracking control for active suspension systems with non-ideal actuators. J. Sound Vib. 2017, 399, 2-20. [CrossRef]

29. Li, H.; Jing, X.; Lam, H.; Shi, P. Fuzzy sampled-data control for uncertain vehicle suspension systems. IEEE Trans. Cybern. 2017, 44,1111-1126.

30. Zhang, Y.; Liu, Y.; Liu, L. Minimal learning parameters-based adaptive neural control for vehicle active suspensions with input saturation. Neurocomputing 2020, 396, 153-161. [CrossRef]

31. Li, H.; Yu, J.; Hilton, C.; Liu, H. Adaptive sliding-mode control for nonlinear active suspension vehicle systems using T-S fuzzy approach. IEEE Trans. Ind. Electron. 2013, 60, 3328-3338. [CrossRef]

32. Na, J.; Huang, Y.; Wu, X.; Su, S.-F.; Li, G. Adaptive finite-time fuzzy control of nonlinear active suspension systems with input delay. IEEE Trans. Cybern. 2020, 50, 2639-2650. [CrossRef]

33. Yao, X.; Yang, Y.; Su, M. A novel adaptive actuator failure compensation scheme based on multi-design integration for half-car active suspension system. Adv. Mech. Eng. 2019, 11, 1-12. [CrossRef]

34. Liu, Y.J.; Zeng, Q.; Tong, S.; Chen, P.L.C.; Liu, L. Actuator failure compensation-based adaptive control of active suspension systems with prescribed performance. IEEE Trans. Ind. Electron 2019, 67, 7044-7053. [CrossRef]

35. Li, W.; Du, H.; Li, W. Four-wheel electric braking system configuration with new braking torque distribution strategy for improving energy recovery efficiency. IEEE Trans. Intell. Transp. Syst. 2019, 21, 87-103. [CrossRef]

36. Gong, J.; Jiang, Y.; Xu, W. Model Predictive Control for Self-Driving Vehicle; Beijing Institute of Technology Press: Beijing, China, 2014.

37. Wang, L. Model Predictive Control System Design and Implementation Using MATLAB; Springer: London, UK, 2009.

38. Wang, Z. Research on Control Strategy and Test Technology of Electromechanical Combined Braking for Electric Drive Tracked Vehicle; Zhejiang University: Hangzhou, China, 2019.

39. Kelly, R.; Haber, R.; Haber-Guerra, R.E.; Reyes, F. Lyapunov Stable Control of Robot Manipulators: A Fuzzy Self-Tuning Procedure. Intell. Autom. Soft Comput. 1999, 5, 313-326. [CrossRef]

40. Türker, T.; Buyukkeles, U.; Bakan, A.F. A Robust Predictive Current Controller for PMSM Drives. IEEE Trans. Ind. Electron. 2016, 63, 3906-3914. [CrossRef]

41. Liu, Y. Research on Model Predictive Control Strategy for Permanent-Magnet Synchronous Machine. Ph.D. Thesis, Huazhong University of Science and Technology, Wuhan, China, 2018. 